\title{
PUBLIC REASON, SCIENCE AND FAITH: THE CASE OF INTELLIGENT DESIGN
}

\author{
(Accepted 16 April 2018)
}

\begin{abstract}
This article considers the justification of laws to religious citizens. It does via a consideration of the debate surround the teaching of Intelligent Design. It argues that one widely held view of political morality, public reason liberalism, requires that schools should allow teaching ID. This is contrary to the views of many defenders of this theory. I show that this argument reveals a deep problem with public reason liberalism, and that it undermines the judgement of the court in the high profile case of Kitzmiller vs Dover.
\end{abstract}

\section{INTRODUCTION}

This paper discusses whether public schools should be permitted, or perhaps required, to teach intelligent design (ID) alongside mainstream Darwinian theory (DT). More specifically, I revisit the question posed by Thomas Nagel:

What would a biology class teach if it wanted to remain neutral on the question of whether divine intervention in the process of life's development was a possibility, while acknowledging that people disagree about whether it should be regarded as a possibility at all, or what probability should be assigned to it...?. ${ }^{1}$

Nagel argues that a properly neutral education system must include the teaching of ID; he believes exclusively teaching DT represents a bias towards a controversial naturalistic viewpoint. Nagel's discussion was extremely controversial and heavily criticised online. ${ }^{2}$ Many theorists believe it is implausible that a widely held liberal principle requires teaching ID; Brian Barry writes:

\footnotetext{
${ }^{1}$ Thomas Nagel, 'Public Education and Intelligent Design', Philosophy and Public Affairs 36, no. 2 (2008), p. 201.

${ }^{2}$ See, http:/ / leiterreports.typepad.com/blog/2009/12/thomas-nagel-jumps-the-shark.html.
} 


\begin{abstract}
Absurd or not, the notion of neutrality has been invoked by the partisans of so-called 'creationist science' in the United States to argue that the Darwinian theory of evolution should be taught as a mere hypothesis and forced to share equal time with the theory that the species was created in a succession by God. On the same basis it might well be urged that the National Science Foundation's budget for astronomy should be split in two, with half going to astrology. For the purposes of both teaching and research, the consensus of the scientific community is precisely what government within a neutral constitutional system should defer to. ${ }^{3}$
\end{abstract}

In this passage Barry expresses a view I term 'Neutral Prohibition' (NP). NP is the position that i) the state must be neutral on metaphysical and theological questions, but nevertheless ii) there are sufficient reasons to prohibit the teaching of ID. In this paper, I mount a series of arguments against NP. My aim is emphatically not to justify teaching ID. I am personally convinced that Darwin should be the basis of the school curriculum. My question is whether there are good grounds to prohibit ID while following principles of neutrality. Given that there are numerous different interpretations of this principle, I focus on the most sophisticated view that might offer support to NP, known as consensus public reason liberalism.

Education policy is a fruitful place to explore question of neutrality and public justification. Steven Macedo writes that debates over religious accommodation and liberal neutrality have played out most 'dramatically' in the educational arena. ${ }^{4}$ In education, the aim of many philosophers and lawyers is to be as inclusive as possible, at least amongst reasonable doctrines. Sometimes this aim conflicts with another valuable goal of education, namely teaching children the best available theories about how the world works, those most likely to be true. In this paper, I show that the conflict between these two aims is deep and that leading attempts to diffuse this tension fail.

While the issue of ID might seem somewhat narrow (although it is worth keeping in mind that it is one that affects many children's lives in a profound way), this paper raises questions that apply more widely to education policy, parental rights and many other matters. My arguments will suggest that much of the recent theoretical treatment of religious pluralism fails to take seriously the nature and scope of disagreement. Important as practices and values are to many believers, religious pluralism is about more than this. Rather, sometimes religious believers also have fundamentally different

\footnotetext{
${ }^{3}$ Brian Barry, A Treatise on Social Justice Vol 2: Justice as Impartiality, (Oxford: Oxford University Press, 1995), p. 161f.

${ }^{4}$ Steven Macedo, Diversity and Distrust: Civic Education in a Multicultural Democracy, (Cambridge: Harvard University Press, 2000), p. 39.
} 
views about how the world works and the nature of causation. ID is a good case to explore this aspect of pluralism, since some people believe that life's creation depends upon supernatural processes, whereas others believe that there is (and perhaps could be no) evidence for such processes and that a belief in them is irrational. Through a discussion of ID, this paper explores the status of science in liberal theory, and I show that the scientific method is itself the object of deep controversy in a way that matters for prominent liberal theories. Finally, the paper explores the nature and implications of public reason, which is one of the central principles in many contemporary views of liberal justice with broad applications to many aspects of law and policy.

\section{BACKGROUND: INTELLIGENT DESIGN AND PUBLIC SCHOOLS}

Proponents of ID believe that the best available explanation of the existence of life is that an external actor directed the creation of living organisms. While technically this actor need not be God, it is assumed to be in most discussions of ID. As such, ID is often thought of as a modern formulation of the theory of Creationism. ${ }^{5}$ Young Earth creationists believe in the literal truth of the biblical story of creation, and hold that the Earth is less than 10,000 years old. ${ }^{6}$ Given U.S. legal precedent, it is sometimes important to ask whether ID is really creationism in a new guise. However, none of my own argument turn on the possible differences between ID and creationism. Estimates vary on the number of people who believe in either Creationism or ID. The precise figure is irrelevant for my argument, but it's important to note that ID is far from a 'fringe' view. A recent Pew survey found that 38 percent of U.S. citizens believe that 'God created man in his present form', with large numbers of other people believing that God played a direct part in creation. $^{7}$

Numerous trials in the U.S. have investigated the legality of public schools teaching ID or creationism. The most recent is Kitzmiller v. Dover in which the court ruled that public schools could not teach ID

\footnotetext{
${ }^{5}$ See, for instance, http://slate.com/articles/news_and_politics/explainer/2005/05/creationism_ vs_intelligent_design.html.

${ }^{6}$ Concise Oxford English Dictionary.

${ }^{7}$ http:/ / pewresearch.org/fact-tank/2017/02/10/darwin-day/.
} 
as an alternative to Darwinian Theory (DT). The judges in Kitzmiller found that teaching ID would violate the Constitution since it would constitute an official state endorsement of religious doctrine. In its judgement, the court went to great lengths to suggest that its decision was not based on a belief about the relative merits of ID versus DT as an explanation of natural events. The presiding judge argued that the truth or falsity of ID was 'a proposition on which the court took no position'. ${ }^{8}$

Because of this claim by the court, the judgment can be considered an instance of NP. Further, the fact that the judgment is suitably neutral plays an important role in justifying the use of coercive power on parents. Note that the court cited the Supreme Court's statement that: 'Families entrust public schools with the education of their children, but condition their trust on the understanding that the classroom will not purposefully be used to advance religious views that may conflict with the private beliefs of the student and his or her family. Students in such institutions are impressionable and their attendance is involuntary'. ${ }^{9}$ Thus while philosophical discussions of neutrality are not directly relevant to the legal reasoning of the case, questions about what constitutes neutrality are highly relevant to determining whether the law is properly justified to citizens of faith. The court here concedes that if it were true that DT conflicted with the private religious views of some citizens, this would be problematic. However, they believed this was not the case. As I discuss later in the paper, the court found that there was no deep tension between religious belief and a belief in evolution, because many scientists and others reconcile the two. In response, I will argue that while some religious views are of course compatible with evolution, the parents can fairly argue that their religious views are not. I will use this to show that such parents can make a reasonable objection to a Darwin-only curriculum. In this discussion and elsewhere I demonstrate how some of the critiques I make against liberal theorists also apply to arguments made in Kitzmiller. This shows how these arguments indicate general concerns with NP, and shows the practical importance of the more technical discussions of neutrality.

\footnotetext{
${ }^{8}$ Kitzmiller v. Dover Area School District, 400 F. Supp. 2d 707, 64 (M.D. Pa. 2005).

${ }^{9}$ Kitzmiller, p. 36.
} 
This paper considers two issues, whether the state should be neutral and whether the state should permit the teaching of ID using public funds. This sets up four possible views.

1. Neutral Prohibition (NP) Yes to neutrality, no to ID

2. Neutral Accommodation (NA) Yes to neutrality, yes to ID

3. Comprehensive Accommodation (CA) No to neutrality, yes to ID

4. Comprehensive Prohibition (CP) No to neutrality, no to ID.

It is worth noting that these labels each include a wide set of possible positions. In particular, there is ambiguity on what is meant by accommodation. I use this to refer the belief that public funds can permissibly support the teaching of ID. This would include teaching ID in publicly controlled schools, or vouchers used to subsidise religious schools teaching ID. This definition creates a further ambiguity in the case of home-schooling. On my terminology, someone who supports the possibility of home-schooling ID but believes it should be banned in schools would not be accommodating the practice. Some might suggest that allowing homeschooling makes school system teaching DT much more justifiable, because religious parents have the option of removing their children from this system. However, Kevin Vallier notes a serious problem which is that the religious parents are paying both for the school system and for their own religious schooling (either in money or in time spent teaching). ${ }^{10}$ This sets up a serious distributive unfairness, which would only be justified if there were a good reason to treat ID differently from DT. But of course, it is precisely this question which is at issue. I therefore believe that if believers in ID can reasonably object to a curriculum teaching only DT without home-schooling, then the addition of this alternative will not be sufficient to assuage their objections. In this paper, I show why neutrality commits the state to accommodation that goes beyond allowing home-schooling, and includes state funded support of ID.

Of the four alternatives, by far the least influential is CA. This position describes the belief that the state ought to be constructed on religious grounds and teach ID for theological reasons. Since this

\footnotetext{
${ }^{10}$ Kevin Vallier, Liberal Politics and Public Faith: Beyond Separation (New York: Routledge 2014), p. 243.
} 
view is not part of liberal discourse I will not discuss it further. Each of the other three positions finds support in the philosophical literature. In the next section I give examples of theorists who defend each of NA and NP from the perspective of public reason liberalism (PRL). The final position, CP, is that favoured by 'liberal perfectionists' who deny the requirement to be neutral and who draw on comprehensive reasons to object to ID. While there are many possible comprehensive objections to ID, the most powerful is the interests of the child. A perfectionist should think that children have a powerful interest in learning the best available theories at school, and most experts believe ID to be a much worse explanation of the existence of life than DT.

By showing NP fails (at least on the best available theories of neutrality) the paper leaves liberals with the choice of either CP or NA. Opting for NA means joining Nagel in the belief that schools should teach ID because of the requirement to be properly neutral. Alternatively, liberals who resist teaching ID should admit that they do so because of scepticism about the merits of ID as an explanation of life. My own personal view is that $\mathrm{CP}$ is the correct choice, but I do not defend that claim in this paper. Given the generality of these labels, the paper does not defend any particular policy response to ID. This paper only shows why NP fails and thereby clarifies which options remain on the table. I show that the policy of prohibiting all public teaching of ID as required by Kitzmiller is not justified in a way consistent with neutrality.

\section{UNDERSTANDING LIBERAL NEUTRALITY: PUBLIC REASON}

Following the publication of Rawls' Political Liberalism, a number of theorists have argued that the state must be neutral between what Rawls termed comprehensive doctrines, paradigmatically religious belief systems. To meet this requirement the state must offer justifications for its law that are acceptable to all reasonable citizens. The justifications are known as public reasons.

Recent years have seen a significant debate within PRL between what are known as the 'convergence' and 'consensus' variants of PRL. Consensus PRL holds that political justification requires that laws are justified through one set of shared reasons. These reasons are appropriately public because all reasonable citizens can appreci- 
ate their force. ${ }^{11}$ Convergence liberalism also requires that each law is justified to each citizen according to reasons she can accept, but on this view the reasons used may differ from person to person. ${ }^{12}$ This difference is highly important in the case of religious reasons. On the consensus view, religious views are ruled out because they cannot be shared by all citizens. In contrast, convergence liberalism permits religious justifications so long as the law can be justified to all persons, including atheists, in terms they can accept. A policy might be justified to a religious citizen in explicitly religious terms but to a secular citizen in a different way.

This more accommodating approach to religious citizens is seen in education policy. Most prominently, convergence liberal Kevin Vallier defends a school choice system on which, 'Parents are free to purchase educational services in an open and competitive education market'. ${ }^{13}$ ID is the example he uses to build his case against common schooling. He argues that some parents will have conclusive reasons to defeat the teaching of ID, but also that some parents have conclusive reasons that defeat teaching only DT. The result is that no common curriculum can be justified to all parents, and the only acceptable solution is to allow different parents to opt for radically different curricula. ${ }^{14}$

In my terminology, Vallier (and likely other convergence PRLs) favours NA. His argument can be understood as showing why the best understanding of neutrality leads to allowing believers in ID to have a school system that accommodates their beliefs. Given that convergence liberals like Vallier do not hold NP, they are not the target of this paper. Instead my arguments offer support to his position because I believe Vallier's view represents a coherent way of meeting the neutrality requirement with respect to ID.

\footnotetext{
${ }^{11}$ Consensus PRL is advanced in Jonathan Quong, Steven Lecce and Matthew Clayton amongst others. See Quong, Liberalism without Perfection, (Oxford: Oxford University Press, 2011). Steven Lecce, Against Perfectionism: Defending Liberal Neutrality, (Toronto: Toronto University Press, 2008). Matthew Clayton, Justice and Legitimacy in Upbringing, (Oxford: Oxford University Press, 2006). While there is some debate about Rawls view, I think he can also be characterised in this way.

12 The most influential defender of the convergence view is Gerald Gaus. See The Order of Public Reason: A theory of freedom and morality in a morally diverse world, Cambridge: Cambridge University Press, 2014), and Justificatory Liberalism: An Essay on Epistemology and Political Theory, (Oxford: Oxford University Press, 2014).

${ }^{13}$ Vallier, Liberal Politics and Public Faith, p. 244.

${ }^{14}$ Ibid., pp. 241-242.
} 


\section{OVERVIEW OF CENTRAL ARGUMENT}

The central argument of the paper is to show that a policy of teaching only DT (and thus excluding ID) cannot be justified by PRL. Specifically, if even consensus PRL requires teaching ID then it follows the most prominent contemporary accounts of liberal neutrality require accommodating ID rather than prohibiting it. This supports my core claim that prohibiting ID requires violating the principle of liberal neutrality.

The steps of my argument are as follows:

1. To be justified in terms of public reason, a law must be justified to all reasonable citizens in terms they could not reasonably reject (liberal principle of legitimacy). ${ }^{15}$

2. Some citizens who believe in ID are reasonable in the relevant sense.

3. Citizens can reasonably reject a law that cannot be justified except by reference to the falsity/implausibility of their comprehensive doctrines.

4. ID is a constitutive element of some comprehensive doctrines

5. Teaching only DT requires asserting the falsity/implausibility of ID. Ergo

6. Teaching only DT can be reasonably rejected by some reasonable citizens. Ergo

7. Teaching only DT cannot be justified in terms of public reason.

Premises 1 and 3 are familiar elements of the consensus PRL view (and political liberalism more generally), and I will simply assume them to be true given that my aim is to show an implication of this view. I will therefore focus on defending premises 2,4 and 5 .

\section{A. Premise 2: Can There be a Reasonable Believer in ID?}

In this section I argue that there can be a believer in ID who counts as reasonable in the relevant sense. The implication is that they count as part of the justificatory community, the set of people to whom laws must be justified. If believers in ID were not reasonable

\footnotetext{
${ }^{15}$ This formulation might seem to suggest that the test of legitimacy applied to all laws, whereas Rawls believed it applied only to constitutional essentials. In response I would note that the issue of ID concerns deep questions about what constitutes promoting a religious view, and thus I think would count as a constitutional essential. Further, note that Jonathan Quong argues for a broader view, in which the test applies to all uses of public power, see his 'The Scope of Public Reason', Political Studies, 52 (2004), pp. 233-245, p. 233.
} 
the state could reject their complaints without imperilling its legitimacy. To say that there can be a reasonable believer in ID might seem surprising, since there are good grounds to think ID is an implausible belief. However, while I agree that ID is a faulty theory, I will show that there can still be a reasonable believer in ID in the relevant sense for PRL.

To do this, I distinguish two aspects of the views of religious believers in ID. First, there is the core religious belief in an activist God. Second, there are the connected beliefs about evolution. An activist God is the kind believed in by people who believe in miracles, a God who intervenes directly and often in the world. Here I show PRLs must consider a belief in this kind of God to be reasonable. In the following section, I show that a belief in ID is a reasonable conclusion given the commitment to an activist God. It will follow that if PRLs grant that the core religious beliefs are reasonable, then the views about science are reasonable as well.

To understand why a belief in an activist God is reasonable in the requisite sense, it is useful to refer to a distinction drawn by Erin Kelly and Lionel McPherson. They distinguish two senses of the reasonable; the political and the epistemic. ${ }^{16}$ Politically reasonable citizens recognise the burdens of judgement (meaning they accept that other citizens will reasonably disagree with them) and endorse basic liberal right. Epistemic reasonableness refers to the objective plausibility of the beliefs of the person in question. Some theorists such as Fabienne Peter have offered variants of PRL which rely strongly on the epistemic component. ${ }^{17}$ On Peter's account, the state is under an obligation to remain neutral between various views which are plausible enough to be counted as reasonable, but does not act wrongly when it denies the truth of implausible and hence unreasonable beliefs.

What are we to make of the claim that a belief in an activist God is epistemically reasonable? Clearly, this is a question well beyond the scope of this paper. Some philosophers have offered accounts on which a belief in God is a justified one. ${ }^{18}$ Others have suggested

\footnotetext{
${ }^{16}$ Erin Kelly and Lionel McPherson, 'On Tolerating the Unreasonable', Journal of Political Philosophy 9, no. 1 (2001).

${ }^{17}$ Fabienne Peter, 'Epistemic Foundations of Political Liberalism', Journal of Moral Philosophy 10, no. 5 (2013), 598-620.

${ }^{18}$ See John Haldane, Reasonable Faith, (London: Routledge, 2004).
} 
many religious beliefs are not reasonable. ${ }^{19}$ Fortunately, we do not need resolve this issue to determine whether a belief in an activist God is reasonable in the requisite sense. This is because views like Peters' cannot possibly offer support to NP. NP means a prohibition on teaching ID while remaining neutral on questions like whether there is a God at all or whether He was active in the creation of life. The epistemic strategy, while a public reason view, does the exact opposite. This approach might well rule out teaching ID, but it will do so precisely because it counts ID as implausible.

In contrast to Peter, the PRLs who are the target of this paper define the reasonable in terms of the political, not the epistemic. There are good grounds for doing this given their ecumenical aims, a concern with the epistemic strategy is that it will rule out far too many beliefs. Many citizens hold beliefs which are poorly justified or somewhat inconsistent. The very same reasons that might lead to a rejection of an intelligent designer also provide reasons to reject beliefs which are fundamental to many religious doctrines, such as reincarnation or resurrection. This is a very important point in the ethical treatment of views like creationism (here I use this term because creationism is more directly opposed to the scientific method). While it's true that creationism challenges a very important part of contemporary science more directly than most religious views, many religious believers hold empirical beliefs that are not plausibly justified according to the scientific method. Ruling all views not justified by the scientific method as unreasonable thus comes at a very heavy cost, since for many theorists, the attraction of liberal neutrality was that the state's policies would be justifiable to all citizens. The epistemic strategy for denying ID undermines this approach and would count many citizens' deepest spiritual beliefs as unreasonable.

Thus, while it is not true that every PRL would accept that a belief in an activist God is reasonable, many (I would argue including Rawls) would do so. ${ }^{20}$ On this view, what makes a citizen reasonable is not primarily the plausibility of their belief system. Instead it is whether they accept the burdens of judgment and value their fellow

\footnotetext{
${ }^{19}$ E.g. Kelly and McPherson, Op Cit.

${ }^{20}$ Note that Rawls writes that we should draw the boundaries of the reasonable as loosely as is possible, and that we should count as reasonable doctrines 'we could not seriously entertain for ourselves' in Political Liberalism: Expanded Edition, (New York: Columbia Press, 2005), p. 59.
} 
citizens as free and equal. Steven Lecce expresses the political variant writing, 'Philosophical enlightenment should not be a precondition of moral status in a society founded on the idea of the social contract'. ${ }^{21}$ On the political view a belief in a God who intervenes directly in the world seems clearly to be a reasonable one. It is a belief held by a very large number of citizens, many of whom are reasoning in good faith and who do not seem to be fundamentally opposed to the liberal project.

Therefore, to even potentially sustain NP, a PRL must define 'reasonable persons' in terms of primarily political not epistemic criteria. If they do this, then they must count a believer in an activist God as reasonable. The question then becomes whether such a citizen could have reasonable grounds to reject a policy of teaching only DT. In my discussions of premises 4 and 5 I demonstrate that they can.

\section{B. Premise 4: Why ID is Constitutive of Some Reasonable Beliefs}

In the above discussion, I showed that PRLs seem bound to accept that at least the religious belief in an activist God is a reasonable one. However, they might still claim that the specific claims that make up ID are unreasonable. To take this approach is to argue that one can separate a citizen's core theological beliefs (in an activist God) from the more peripheral beliefs about the creation of life. Following this, it would be possible to claim that the former set of beliefs are reasonable even though the latter are not. This would have the following application in practice. Courts could claim that they took no view at all on the core questions of religious truth. Thus, the law forbidding the teaching of ID takes no view at all on the question of whether there is a God and whether He intervenes in the world. All that the court takes issue with is the specific views about evolution. Believers in ID could not, per this argument, suggest that the law was justified in a way incompatible with their deepest beliefs but only with a more peripheral part of their belief set.

In response to this argument, I will suggest it is extremely problematic to separate the belief in an activist God from the belief in ID. In the minds of some believers, ID represents one of the most

\footnotetext{
${ }^{21}$ Steven Lecce, Against Perfectionism: Defending Liberal Neutrality, (Toronto: University of Toronto Press, 2008), p. 173.
} 
important acts of God. Further, I will show that their belief in ID is not irrational given their belief in an activist God. For such believers, ID is a core and constitutive part of their comprehensive doctrine. By this I mean that while other Christians fully accept evolution, we should count these other Christians as holding a different comprehensive view from those who believe in ID. Forcing the children of believers of ID to learn DT thus does entail teaching children a different comprehensive doctrine from the one held by their parents. $^{22}$

The importance of ID to the believer can be evidenced in part the lengths to which they have gone to resist the teaching of DT, right up to fighting the case in Kitzmiller. The long running and still ongoing struggle some believers make to the teaching of science is sufficient to show that at least they believe that some elements of mainstream science are incompatible with their religious view. Despite this, one could dismiss these beliefs about ID on the grounds that these people misunderstand the implications of their own faith. Rawls and most other PRLs (including convergence PRLS) allow justifications that assume away objections based on clearly erroneous or mistaken reasoning. ${ }^{23}$ This is why I suggested that their view of reasonableness was primarily, not wholly, political. It does have epistemic elements, but the epistemic criterion is just to reason adequately from one's own belief system, it is not a criterion that subjects theological beliefs to epistemic scrutiny. However, I believe given the belief in an activist God, a person reasoning adequately could come to believe in ID. This matters because if they were making an obvious error about the implications of their own belief system then their concerns might be dismissed, but since they are not, either PRLs must impugn their core religious views (which I argued above they would not) or they must accept that a belief in ID is reasonable.

My argument here echoes a claim made by Nagel who writes that:

ID (as I shall call it, in conformity to current usage) is best interpreted not as an argument for the existence of God, but as a claim about what it is reasonable to believe about biological evolution

\footnotetext{
22 There are complex questions raised by remarks about counting two Christian doctrines as different views, but note that it is morally problematic to teach Catholicism to the children of Protestant parents.

${ }^{23}$ See Rawls, Political Liberalism, pp. 55-58. Also see Gaus' on 'modest idealization', The Order of Public Reason, p. 276.
} 
if one independently holds a belief in God that is consistent both with the empirical facts about nature that have been established by observation, and with the acceptance of general standards of scientific evidence. ${ }^{24}$

One way of thinking about Nagel's argument here would be to make a distinction between two ways of thinking about the claim that 'people are justified in believing ID'.

(i) Strong ID thesis whatever their starting point, individuals have good reason to accept that an outside actor intervened in the creation of life.

(ii) Weak ID thesis If we assume and hold fixed certain religious commitments then individuals have good reason to accept that an outside actor intervened in the creation of life.

My claim that ID is reasonable for the purposes of PRL requires only that the weaker thesis is true. To see why it is consider this analogous case:

Bolt from the blue: Imagine that John sees a lightning bolt in the sky on a day with predominantly clear blue skies. Further, suppose it turns out that this lightning bolt hit a member of the public, Ulysses. Going to his local meteorologist, John discovers that there is in fact a scientific explanation of the event but it is highly unlikely. The scientist suggests that the type of event described has a probability so low that it would be expected only once in one million years. Despite these long odds, if John is an atheist it would still seem rational to accept that he had witnessed an incredibly rare natural event and that Ulysses has been spectacularly unlucky. However, now assume that John is a believer in the ancient Greek gods. Specifically, he believes that Zeus exists and that he is prone to unleash lightning bolts on the unworthy. Finally, suppose that Ulysses had knowingly stolen a sacred calf.

I believe that if we hold fixed John's belief in Zeus then from his perspective the best explanation of these events is that Zeus caused the lightning bolt to hit Ulysses. It does not follow from this argument that it is fully rational for John to accept this religious explanation, and certainly not that other citizens should accept this conclusion because of his testimony. Many citizens would think that this lightning bolt does not constitute any 'evidence' for the existence of Zeus at all. The point of this example is that our problem with John's religious explanation is in the assumption that there is a

\footnotetext{
${ }^{24}$ Nagel, 'Public Education and Intelligent Design', p. 188.
} 
super-powered being called Zeus, not with the peripheral belief about how Zeus might act towards Ulysses.

In the case of ID, if a person believes in a certain kind of activist God then it seems entirely sensible to accept the proposition that $\mathrm{He}$ was active in the creation of life. Opponents of ID might complain that there is evidence that no creator was required in the creation of life, but presumably it would always be true that any set of evidence is at least consistent with the action of an all-powerful creator. Of course, just as in the case of Zeus raised above, citizens can have very good reasons to reject ID. The point is not to show that other citizens should abandon their objections to ID. Instead the example demonstrates that the objections of other citizens to ID will, at least in part, be to the core aspects of the believer in ID's religious belief. Since I have shown earlier that this core belief must be considered reasonable from a political point of view, it follows that the specific beliefs must be counted as reasonable as well, since they are reasoned adequately from a reasonable view.

I have now demonstrated that that on the views of those PRL who are the target of this paper a belief in ID is, at least in principle, a reasonable one. In well-ordered liberal societies we should expect wide disagreement over the existence and nature of God. One of the beliefs we should expect to be present is a belief in an interventionist and activist God. Given a belief in a God of this kind, a reasonable citizen who is reasoning adequately could come to the belief that ID is the best explanation of life, and this belief could form a core part of their comprehensive beliefs. ${ }^{25}$

\section{Premise 5: Can proponents of Intelligent Design reasonably be expected to accept the teaching of evolution?}

The above sections have shown both that a belief in ID can be reasonable, and that it can form a core part of a person's comprehensive doctrines. Together, these premises show that if a believer in ID can reasonably reject a policy of only teaching DT then such a policy will be ruled illegitimate by PRL. In this section I show that

\footnotetext{
${ }^{25}$ Joseph Heath has considered cases of this kind in the context of political liberalism. Discussing the religious belief in reincarnation, and the implication that people can be responsible for their natural endowments he writes 'while this worldview may not be scientific, it clearly belongs to a 'reasonable' comprehensive doctrine in Rawls' sense of the term'. See Heath, 'Political Egalitarianism', Social Theory and Practice, 34 (2008), p. 501.
} 
such believers can indeed make such a reasonable rejection. I take for granted that a citizen can reasonably reject a law which is premised on a rejection of her comprehensive view, my arguments show why teaching only DT constitutes a rejection of some reasonable comprehensive beliefs.

In the terminology of PRL, I will argue that the position taken by the court in Kitzmiller was not 'freestanding' from the underlying metaphysical debates. Rather, the decision was deeply enmeshed in metaphysical issues. To show this, consider what it would mean for a policy to be freestanding from comprehensive debates between reasonable citizens. I suggest that a good way of assessing whether a policy is freestanding is to ask whether it could plausibly be held by a reasonable citizen no matter what their comprehensive doctrine. If it could, then it is properly freestanding. On the other hand, if we can only reasonably expect someone to support this policy if they hold a specific comprehensive doctrine, or if they do not hold one specific comprehensive belief, then the justification for the policy is not freestanding in the right way.

Consider a distributive principle such as the sufficiency principle. This principle holds that it is a basic requirement of justice that all have enough resources to live a reasonably good life. The state must ensure that all citizens have access to housing, education and healthcare, and that all citizens either have access to employment opportunities or are directly provided money by the benefits system. Now suppose that you meet someone who believes that the sufficiency principle is indeed a requirement of justice. Ask yourself what knowing that they endorse the sufficiency principle tells you about their core metaphysical or theological beliefs. The answer is 'very little'. After all, the sufficiency principle might be justified in a variety of different ways. Some people might accept the sufficiency principle because they believe that God requires that no one is left with too few resources to live a decent life. Others might believe that the sufficiency principle maximises welfare. Still others might accept the sufficiency principle for purely pragmatic reasons, believing that the stability of the state would be threatened by the presence of large numbers of impoverished people. The sufficiency principle thus seems appropriately modular, it is something that could be accepted by someone holding essentially any comprehensive doctrine. 
In contrast, consider the ID debate. Imagine someone who believes that schools should teach only ID (or indeed Creationism) then consider what this political belief tells you about their metaphysical commitments. They are extremely suggestive of the fact that they believe in a literalist view of the bible. This is not certain; perhaps they believe schools should teach Creationism for some other reason. They might believe that children who are taught Creationism as part of a Christian upbringing are likely to grow up into better democratic citizens. Nevertheless, this belief seems strongly predictive of having a certain comprehensive view (and I confidently assert that most people who support teaching Creationism or ID do in fact hold a religious comprehensive view).

Importantly, many liberal thinkers share my judgement about this matter. They believe that teaching ID or creationism is tantamount to state endorsement of a religious comprehensive view. Amy Gutmann argues that 'teaching creationism as science - even as one of among many reasonable scientific theories - violates the principle of non-repression in indirectly imposing a sectarian religious view on all children'. ${ }^{26}$ For Gutmann, the mere fact that there might be some grounds of public reason to support creationism are not sufficient to count teaching ID as a neutral policy. She believes that citizens who do not share these religious sectarian beliefs can reasonably reject teaching ID. ${ }^{27}$

The situation is more complex when we consider someone who believes that schools should teach only DT. The reason is that it is entirely possible to be both a devout religious believer and a believer in evolution. DT is thus considerably more ecumenical than is ID or creationism. Therefore, it might seem that a policy of teaching only DT is suitably freestanding, because teaching DT is compatible with the views of atheists and of devout believers it does not seem to press any sectarian view.

An argument of this kind is suggested by the court in Kitzmiller. The judge wrote that:

'Both defendants and many of the leading proponents of ID make a bedrock assumption which is utterly false. Their presupposition is that evolutionary theory is antithetical to a belief in the

\footnotetext{
${ }^{26}$ Amy Gutmann, Democratic Education, Rev. ed. (Princeton, N.J. : Princeton University Press, 1999), p. 102 .

${ }^{27}$ I discuss creationism in this passage because it is the language Gutmann uses in the quoted passage (written before ID becomes prominent), but I believe she and other like-minded liberals would object to state endorsement of ID for similar reasons.
} 
existence of a supreme being and to religion in general. Repeatedly in this trial plaintiffs' scientific experts testified that the theory of evolution represents good science, is overwhelmingly accepted by the scientific community, and that it in no way conflicts with, nor does it deny, the existence of a divine creator. ${ }^{28}$

Here the court claims that because someone could accept both DT and Christianity teaching DT is an appropriately neutral decision. However, this conclusion does not follow. While a belief in DT is indeed compatible with the beliefs of many religious believers, it is not compatible with the religious beliefs of the proponents of creationism or ID. After all, their belief is that God's intervention throughout the process was a necessary aspect of the creation of life, whereas the teaching of DT suggests precisely the opposite.

These believers thus can reasonably argue that teaching only DT is antithetical to their beliefs. And their reasonable objections are highly significant. PRLs ask whether any reasonable citizen can make a reasonable complaint. The fact that a majority of reasonable citizens can accept that policy is, in this context, irrelevant. Consider an analogous case, in which the state had a policy that promoted teaching the view that there was only one God. One could claim this policy was not sectarian because it was compatible with a whole range of monotheistic faith including Christianity, Judaism and Islam. Numerically, this range of faiths covers a large majority of the comprehensive beliefs in the contemporary United States. While true, this clearly does not make the decision to teach monotheism appropriately public because there are many reasonable doctrines with which it conflicts. A Hindu citizen would have patently reasonable grounds to reject such a curriculum. Similarly, while there are many devout Christians whose beliefs are entirely compatible with a belief in evolution, this does not make the decision to teach DT neutral with respect to those whose spiritual beliefs include the view that God directly created life on Earth.

The mere fact that there is a way to remain 'Christian' in some sense does not seem to assuage the fact that society is using the school system to promote a specific religious conception which is not held by some citizens. This concern is expressed by Eammon Callan who considers the political requirements of Rawls' view from the perspective of citizens of faith. He writes:

\footnotetext{
${ }^{28}$ Kitzmiller, p. 136.
} 
The education they want for their children is one that perpetuates a way of life in the particular form they cherish. The fact that reasonableness might cohere with some altered form will not placate them. Scottish Calvinists of the seventeenth century would be horrified at what many of their American descendants take to be a Protestant faith. Contemporary religious conservatives might feel a comparable horror at the prospect of a faith their children could one day have. ${ }^{29}$

Therefore, the claim that DT is compatible with a belief in God is not sufficient to show that teaching only DT is freestanding. While it may well be true that for many people religious belief is entirely compatible with evolution, for some believers these thing are not compatible. Because of this, just as Gutmann believes that teaching ID would amount to a sectarian imposition of a world view she and others disagree with, so too can these reasonable believers in ID complain that teaching DT is an imposition of a worldview with which they disagree. Therefore, I have shown both that there can be reasonable believers in ID, and that they can have reasonable objections to teaching only DT. This is sufficient to show that teaching only DT is illegitimate according to PRL.

\section{POSSIBLE REPLIES}

In the final section I consider three possible replies to my argument. I will suggest that while both are important in other areas of debate, neither can ground a defence of NP.

\section{A. Instrumental Benefits of DT}

The first possible reply draws on the instrumental benefits garnered by teaching DT rather than ID. Widespread belief in ID might lead to a distrust of mainstream scientists. Deterioration in scientific aptitude would be relevant from a political point of view for a variety of reasons. It might cause a loss in the ability of the economy to produce certain primary goods such as healthcare, and might undermine the ability of citizens to reason successfully on public matters with a scientific component.

The attraction of this reply is that it offers a justification for teaching only DT that is consistent with the requirements of public reason. The values of medical advances, social productivity or democratic citizenship are not ones that depend on holding a certain

\footnotetext{
${ }^{29}$ Eamonn Callan, Creating Citizens: Political Education and Liberal Democracy, Oxford Political Theory (Oxford: Clarendon Press, 1997), p. 39.
} 
conception of the good. Instead, benefits of this kind are things that all citizens can reasonably be expected to see as a good reason to pursue a specific policy.

The proposed argument is similar to Rawls' treatment of the issue of school prayer. He notes that while a political liberal state must block a requirement to have school prayer because it would encourage children to hold a certain religious view, school prayer might be permissible if it was justified because of public benefits such as a more productive or engaged citizenry, or because collective prayer fosters community spirit. ${ }^{30}$ This shows that PRLs can, perhaps, accept seemingly sectarian education if the aims are suitably public.

However, there is a crucial difference between the case of school prayer and that of teaching DT over ID. The difference is that the supposed benefits of prayer obtain independently of the truth of Christianity or any other religion. If it is true that communal prayer fosters a community spirit, this effect is valuable whether or not God exists. This is not the case in ID. If believing in DT would advance scientific understanding or produce medical benefits this is only because DT is true (or just a better explanation of many phenomena than is ID).

This difference matters because it means that a position on the underlying comprehensive debate (whether we ought to believe in DT or ID) must be part of the premise of the argument. While the goal of public policy would be appropriately neutral, its justification would be deeply sectarian. This is sufficient to rule the law as illegitimate, because the public reason constraint applies to the reasons given to justify a law, not merely that law's goals. Rawls writes, 'when the premises (emphasis mine) and conclusions are not acceptable on due reflection to all parties in disagreement, valid argument falls short of public justification'. ${ }^{31}$

Further, note that in many cases the instrumental benefits of teaching are not considered sufficient to outweigh potential objections from parents. Suppose that there were instrumental benefits attached to believing one religion rather than another. Perhaps the protestant work ethic really does encourage children to try harder

\footnotetext{
${ }^{30}$ Rawls, Political Liberalism, p. 474.

${ }^{31}$ John Rawls and Erin Kelly, Justice as Fairness : A Restatement (Delhi: Universal, 2004), p. 27.
} 
and get better jobs. This fact taken alone would not be seen as sufficient to justify a government backed campaign to promote Protestantism to children of Catholic parents. Instead, a parent's moral right to object to a curriculum that is antithetical to their views is seen as extremely weighty, and thus outweighs (at least minor) instrumental benefits. If my main arguments are sound, then parents who believe in ID could suggest that even if it were true that learning DT had some benefits in terms of job prospects, this would not be sufficient to show why the state had moral permission to teach a curriculum that was hostile to their conception of the good.

Therefore, I suggest that the mere fact that a policy aims at some instrumental benefits is not sufficient to render it legitimate within PRL. While the aim of teaching DT for the promotion of medicine and science is legitimate, the arguments used to show why this policy of would have these benefits are necessarily illegitimate. This strategy would also explicitly take a view on the relative plausibility of DT and ID, and thus it does not provide a way of defending NP.

\section{B. Teaching and Truth}

Another point worth reflecting on is that school curricula often includes many elements which are not 'true', as according to the best experts. The versions of economics or physics taught to teenagers contain many simplifications and in some cases wide divergences from higher level accounts of the same issues. This matters in the following sense: above I suggested that the state teaching DT implicitly suggested that the state accepted that DT was 'true'. But given that many aspects of the curricula are not true, this claim looks implausible. Rather, we might think that the curriculum merely teaches in a way which is useful to create a certain mode of thinking, to 'think like a physicist'. ${ }^{32}$ If the state does not claim that DT is true by teaching it in schools, then it might be that objections to its teaching lose force.

While this issue is pedagogically interesting, I do not think this observation can save NP. This is because there is a big difference with teaching simplified versions of physics, as opposed to quantum physics, and teaching DT rather than ID. In the physics case, the

\footnotetext{
${ }^{32}$ I thank an anonymous reviewer for this point.
} 
school curricula is taught as an approximation of the truth. That is, there is broad agreement on what counts as the best available theory, and agreement this theory is too complex for kids and thus a need to teach a somewhat simpler version, or even a version that is wrong in important respects. In the case of ID, there is deep disagreement on whether it is permissible to appeal to an outside actor in explaining phenomena. The point is that while many things taught in schools are not 'true', they are believed by relevant experts as things that children have epistemic reason to believe. Conversely, believers in ID or creationism would not accept that people have most reason to believe in DT, because they believe that DT misses important parts of the causal story. The state teaching DT as something that children have reason to endorse thus does assert a proposition to which the believer in ID is deeply opposed, even if the state does not claim that ID is 'true'. ${ }^{33}$

\section{A Theological Mistake?}

A final reply worth considering relies on the argument that believers in creationism or ID are in some fundamental sense mistaken about the implications of their own belief system. In the philosophical literature, this response is explored by Warnick and Fooce who argue that current, modern understandings of religious texts - in particular, the Bible - are based on a faulty method of interpretation. The modern reading of texts seems to suggest that religious texts present an actual account of events and are therefore contradictory to scientific understandings. However, a deeper understanding of the historical context of religious texts suggests that they should not be seen in this way. On the modernist view, 'Genesis is taken to be an accurate description of an independent event' and 'this modernist reading of Genesis is what compels some believers to see it as an alternative to evolution' ${ }^{34}$

In light of this, Warnick and Fooce argue though that this reading is inappropriate since sacred texts were written according to premodern standards. They add that, 'Pre-moderns understood sacred

\footnotetext{
${ }^{33}$ Further, it is also worth noting that unlike the physics case most biologists do believe that evolution is true, or at least the theory we currently have most reason to endorse. They do not teach DT as merely a proxy of the best view, but rather an important component of the best view.

${ }^{34}$ Bryan R. Warnick and C. David Fooce, 'Does Teaching Creationism Facilitate Student Autonomy?', Theory and Research in Education 5, no. 3 (2007), p. 366.
} 
texts not so much as something which refers to the sacred, but something which incarnates or enacts the sacred. ${ }^{35}$ On this understanding, model sacred texts are taken to be more analogous to poetry than science text books, and are attempts to capture the significance and emotions of events rather than to depict exactly how they occurred in the physical world. Hence teaching children the story of Genesis as literal fact is not (only) bad science, but also bad theology and fails to instantiate the religious practice in the way its proponents would presumably wish to do.

But this line of response cannot save NP. If Warnick and Fooce are correct, then believers who take a literalist interpretation of Genesis are mistaken about both the correct reading of the Bible and the right way to understand the creation of life. While this may be true, it is fairly obviously not a reason that is freestanding from theological debates.

Interestingly, Matthew Clayton and David Stevens suggest that sometimes PRLs must make this kind of move. They consider cases in which religious citizens believe that God commands them to take actions that are inconsistent with a liberal society. They argue that the right reaction in this case is for the state to take issue with the core religious beliefs at stake and they council the liberal state to use explicitly religious reasons which would presumably include those discussed by Warnick and Fooce in the case of ID. They write:

Despite Rawls's attempts to be non-sectarian ... political liberals must be committed to rejecting certain comprehensive claims, at least if and when they confront the liberal view. And, they must be rejected as false and not as merely reasonable. This is a significant change to the ordinary portrayal of political liberalism as eschewing any appeal to, or engagement with, the content of comprehensive conceptions. ${ }^{36}$

This is an extremely interesting development within PRL, which as the authors rightly note, represents a major shift from most PRL discourse. In the context of this paper, the most important thing to note is that by taking this step Clayton and Stevens abandon NP. The arguments of Warnick and Fooce, or other theological arguments, are explicit denials of ID. Admittedly, these arguments come from a shared theological cannon and might be more acceptable in some sense to the proponents of ID for this reason. As such, the Warnick

\footnotetext{
${ }^{35}$ Ibid., p. 360.

${ }^{36}$ Clayton, Matthew and Stevens, David, 'When God Commands Disobedience', Res Publica 20, no. 1 (2014), p. 79.
} 
and Fooce argument might be a particularly effective form of $\mathrm{CP}$, but it is explicitly a strategy that confronts ID on its merits rather than showing why ID can be prohibited while remaining neutral on religious matters. For this reason, Warnick and Fooce cannot support an argument like the one deployed by court which purported to take no view about the plausibility of creationism or ID. Therefore, whatever the merits of this approach it does not challenge my central conclusion that NP fails.

\section{CONCLUSION}

This paper has suggested that there is a deep tension between the ideal of liberal neutrality and the policy of prohibiting the teaching of intelligent design. This tension matters in practice, since neutrality is held to be significant in justifying the use of coercive force to parents of religious faith. If the neutral prohibition strategy succeeds, the state can justify banning intelligent design in a way that does not conflict with the religious commitments of its citizens. On this account, the parent's objections are misguided and can be properly ignored. In contrast, this paper has suggested that parents rightly claim that teaching evolution undermines core aspects of their faith. Even though some citizens of faith can reconcile a belief in God with a belief in evolution, this does not imply that a secular scientific curriculum is justifiable to those whose religious commitments cannot be reconciled with Darwinian theory.

A broader conclusion of the paper is that liberals cannot help themselves, as Barry did, to mainstream scientific opinion as an unproblematically neutral starting point for discussion without further argument. As history has repeatedly shown, scientific conclusions can be deeply controversial with religious citizens. This has potential implications for a number of ongoing political debates in which left liberals appeal to science as a neutral arbiter, for instance debates over abortion and the use of stem cells. My own belief is that the scientific view does indeed represent the best basis for the curriculum and for public policy, but this paper has suggested that using it might require changing or weakening the liberal commitment to neutrality. In this way, the paper forms part of a growing set of arguments that suggest that the commitment to neutrality imagined by PRLs might too demanding, and that while a limited form of 
neutrality may be applicable, the state must sometimes take sides on disputed questions of value and of metaphysics. ${ }^{37}$ I have demonstrated that an important set of cases for neutrality are those, like ID, when the disagreement is not merely about value. Further work on the substance of different religions is required to properly explore these further questions, but this paper demonstrates that taking all 'comprehensive beliefs' or conceptions of the good to be structurally similar is not be the best way to proceed with the required analysis. Religions are very different from merely ethical theories, and taking them seriously requires acknowledging this.

\section{OPEN ACCESS}

This article is distributed under the terms of the Creative Commons Attribution 4.0 International License (http:// creativecommons.org/licenses/ by/4.0/), which permits unrestricted use, distribution, and reproduction in any medium, provided you give appropriate credit to the original author(s) and the source, provide a link to the Creative Commons license, and indicate if changes were made.

University of Bristol, 11 Priory Rd, Clifton, Bristol, BS8 1TU, UK

E-mail: tim.fowler@bristol.ac.uk

\footnotetext{
${ }^{37}$ For other arguments of this form see Tadros, Wrongs and Crimes, (Oxford: Oxford University Press, 2016), especially chapter 8 and Alan Patten, 'Liberal neutrality: A reinterpretation and a defence', The Journal of Political Philosophy 20, pp. 245-272.
} 